\title{
Computed tomography after severe COVID-19 pneumonia: findings at 6 months and beyond
}

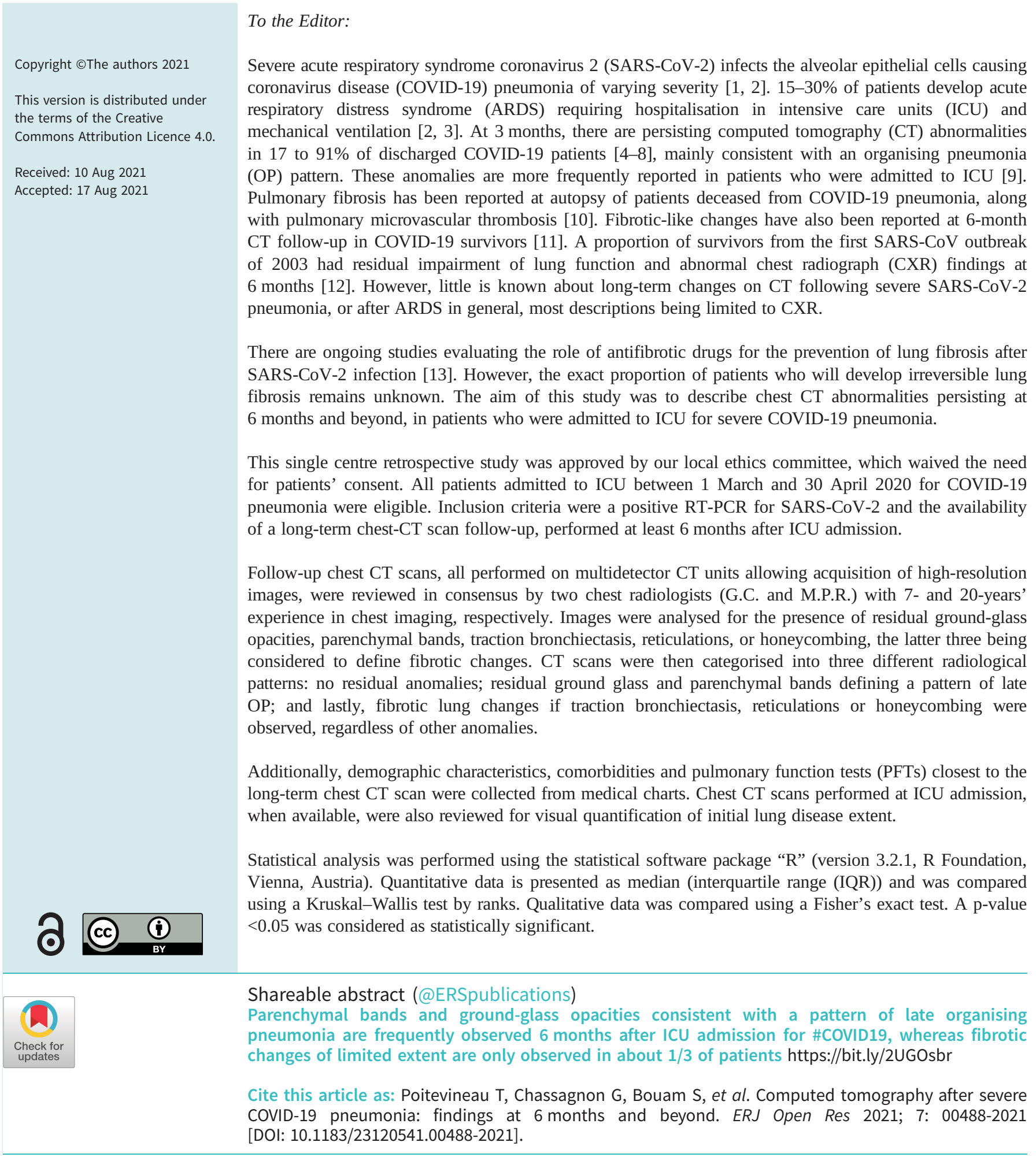


A total of 126 COVID-19 patients were admitted to ICU during the study period. Management of ARDS was standardised, in accordance with the guidelines from the French Intensive Care Society [14]. Of these patients, 20\% (26/126) died. Of the remaining 100 patients, 51 were transferred outside the institution after ICU and lost to follow-up. Six patients had CT scan normalisation during the 6-month period following ICU discharge and were not re-evaluated afterwards. The remaining 43 patients had a late follow-up chest CT scan and composed the study sample. Their characteristics are summarised in the table 1.

The study sample was mostly composed of men $(32 / 43,74 \%)$ and the median age was 56.0 years (IQR 50.5-64.0 years). Most patients had comorbidities (35/43, 81\%), the most common being diabetes (21/43, 49\%). The median length of stay in ICU was 15 days (IQR 9-32 days) and 77\% of the patients (33/43) were intubated.

Follow-up PFTs were available for 39 of the 43 patients. They were performed at a median time interval of 7.9 months (IQR 6.2-10.0 months) from ICU admission. Most patients had normal total lung capacity (35/ 39, 90\%) and forced vital capacity (33/39, 86\%). Measurement of diffusing capacity of the lung for the lung monoxide $\left(D_{\mathrm{LCO}}\right)$ was available for 38 patients and was abnormal $(<80 \%$ of predicted value) in $82 \%$ of them (31/38). The median $D_{\text {LCO }}$ value was $64 \%$ predicted (IQR $50-76 \%$ predicted).

The median time-interval between ICU admission and late CT follow-up was 7.1 months (5.9-9.1 months). Late CT scans showed normalisation in 28\% of patients (12/43). Nine of these 12 patients had $D_{\text {LCO }}$ measurements, which were abnormal in one third (3/9), despite apparent CT normalisation. A late OP pattern, with a variable association of residual ground glass and parenchymal bands but no fibrotic changes was observed in $44 \%(19 / 43)$ of the patients (figure 1). Lastly, fibrotic changes were found in $28 \%$ of

TABLE 1 Patient characteristics and follow-up findings

\begin{tabular}{|c|c|c|c|c|c|}
\hline & All & Normal & Late OP pattern & Fibrosis & $\mathrm{p}$-value \\
\hline Subjects $n$ & 43 & 12 & 19 & 12 & \\
\hline Age, years & $56.0(50.5-64.0)$ & $56.0(46.0-63.3)$ & $55.0(51.5-64.0)$ & $62.0(50.5-63.5)$ & 0.816 \\
\hline Male gender & $32 / 43(74)$ & $9 / 12(75)$ & $13 / 19(68)$ & $10 / 12(83)$ & 0.755 \\
\hline Smoker & $13 / 39(33)$ & $6 / 11(55)$ & $3 / 16(19)$ & $4 / 12(33)$ & 0.149 \\
\hline \multicolumn{6}{|l|}{ Comorbidities } \\
\hline Diabetes & $21 / 43(49)$ & $6 / 12(50)$ & $12 / 19(63)$ & $3 / 12(25)$ & 0.146 \\
\hline Hypertension & $17 / 43(39)$ & $5 / 12(42)$ & $8 / 19(42)$ & $4 / 12(33)$ & 0.925 \\
\hline Obesity & $10 / 43(23)$ & $3 / 12(25)$ & $5 / 19(26)$ & $2 / 12(17)$ & 0.902 \\
\hline Cardiovascular disease & $11 / 43(26)$ & $3 / 12(25)$ & $7 / 19(37)$ & $1 / 12(8)$ & 0.222 \\
\hline Chronic respiratory disease & $3 / 43(7)$ & $1 / 12(8)$ & $0 / 19(0)$ & $2 / 12(17)$ & 0.164 \\
\hline Cancer & $8 / 43(19)$ & $5 / 12(42)$ & $2 / 19(11)$ & $1 / 12(8)$ & 0.066 \\
\hline Disease extent on initial CT scan & & & & & 0.003 \\
\hline$<50 \%$ & $19 / 33(58)$ & $9 / 9(100)$ & $7 / 13(54)$ & $3 / 11(27)$ & \\
\hline$>50 \%$ & $14 / 33(42)$ & $0 / 9(0)$ & $6 / 13(46)$ & $8 / 11(73)$ & \\
\hline Length of ICU stay, days & $15(9-32)$ & $12(3-17)$ & $19(11-32)$ & $24(11-49)$ & 0.179 \\
\hline Tracheal intubation & $33 / 43(77)$ & $8 / 12(67)$ & $14 / 18(78)$ & $11 / 12(92)$ & 0.404 \\
\hline Delay between ICU admission and follow-up CT, months & $7.1(5.9-9.1)$ & $7.5(6.4-9.8)$ & $6.8(6.0-8.7)$ & $7.3(5.5-9.2)$ & 0.668 \\
\hline \multicolumn{6}{|l|}{ CT findings } \\
\hline Ground-glass opacities & $29 / 43(67)$ & $0(0)$ & $17 / 19(89)$ & $12 / 12(100)$ & \\
\hline Parenchymal bands & $26 / 43(60)$ & $0(0)$ & $15 / 19(79)$ & $10 / 12(83)$ & \\
\hline Traction bronchiectasis & $12 / 43(28)$ & $0(0)$ & $0(0)$ & $12 / 12(100)$ & \\
\hline Reticulations & $5 / 43(12)$ & $0(0)$ & $0(0)$ & $5 / 12(42)$ & \\
\hline Delay between ICU admission and follow-up PFTs, months & $7.9(6.2-10.0)$ & $8.1(6.4-10.1)$ & $6.8(5.8-8.5)$ & $10.0(8.3-10.8)$ & 0.024 \\
\hline \multicolumn{6}{|l|}{ Follow-up PFTs results } \\
\hline Impaired TLC & $4 / 39(10)$ & $1 / 9(11)$ & $0 / 19(0)$ & $3 / 11(27)$ & 0.035 \\
\hline$\%$ of predicted TLC & $93(85-96)$ & $93(90-96)$ & $93(88-96)$ & $93(81-98)$ & 0.693 \\
\hline Impaired FVC & $6 / 39(14)$ & $1 / 9(11)$ & $1 / 19(5)$ & $4 / 11(36)$ & 0.073 \\
\hline$\%$ of predicted FVC & $94(83-105)$ & 97 (87-99) & $94(84-105)$ & $94(74-105)$ & 0.810 \\
\hline Impaired $D_{\mathrm{LCO}}$ & $31 / 38(82)$ & $6 / 9(67)$ & $16 / 18(89)$ & $9 / 11(82)$ & 0.361 \\
\hline$\%$ of predicted $D_{\mathrm{Lco}}$ & $64(50-76)$ & $78(67-83)$ & $64(51-75)$ & $61(45-70)$ & 0.138 \\
\hline
\end{tabular}



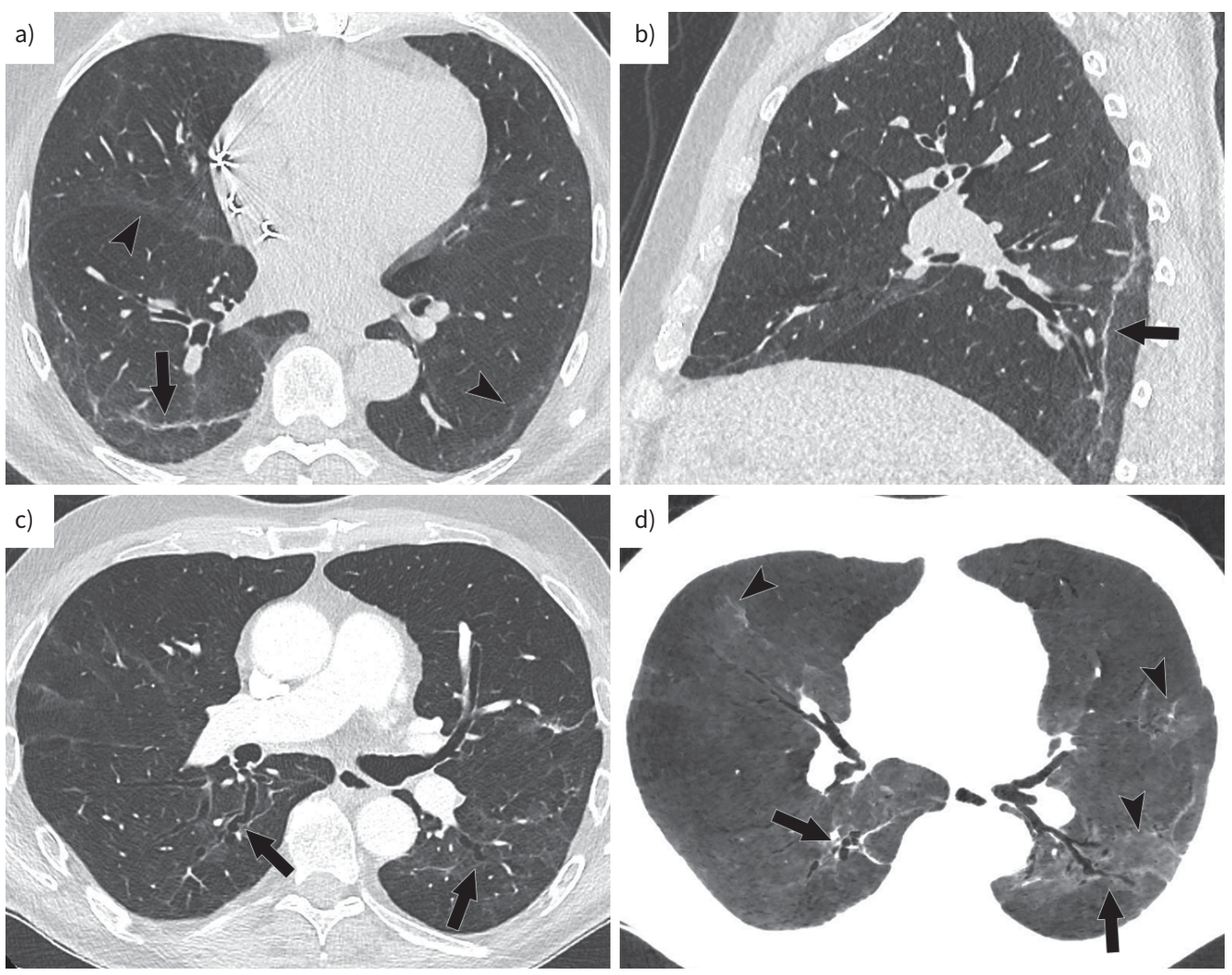

FIGURE 1 Axial ( $a, c, d$ ) and sagittal (b) images demonstrating late changes on CT. a, b) Late organising pneumonia pattern is characterised by the association of residual ground glass (arrow heads) and parenchymal bands. c, d) Fibrotic changes consist of the association of traction bronchiectasis (arrows) with ground glass.

patients (12/43) overall and were of limited extent, involving $<10 \%$ of lung parenchyma on visual assessment. They consisted of traction bronchiectasis within residual ground-glass opacities in all 12 patients (100\%), associated with reticulations in five patients (42\%). 10 patients also had parenchymal bands (83\%).

There was a trend towards a longer ICU stay in patients who developed fibrotic lung changes (24 days (IQR 11-49 days) versus 19 days (IQR 11-32 days) for patients with late OP without fibrotic changes and 12 days (IQR 3-17 days) for patients with CT normalisation at 6 months, $\mathrm{p}=0.179$ ). The proportion of patients who had pneumonia extent $>50 \%$ on initial CT was significantly higher among those with late fibrotic changes: 8/11 (73\%) versus 6/13 (46\%) for patients with late OP and 0/9 (0\%) for patients with CT normalisation, $\mathrm{p}=0.003$.

The strength of this retrospective study was its focus on severe COVID-19 patients who were admitted to ICU. The proportion of patients with residual abnormalities at 6 months in our cohort is in line with other reports from China $[11,15]$. However, despite focusing on a population admitted to ICU, we found a lower proportion of patients with late fibrotic changes (28 versus up to 35\%) and these changes were of limited extent. The difference may be related to a more restrictive definition of fibrotic changes in our study. Indeed, parenchymal bands were considered as fibrotic-like changes in the studies by Han et al. [11] and LiU et al. [15], whereas we considered them as residual signs of OP, observed from the early phase of the disease and improving over time, unlike traction bronchiectasis [16].

Our study has several limitations. First, owing to its retrospective design, late chest CT scan and PFTs follow-up were not available for all COVID-19 patients admitted to ICU during the study period. Patients transferred to other hospitals were lost to follow-up. However, for those followed-up onsite, late fibrotic changes were of limited extent, when observed, which is worth noting. Secondly, patients in the early phase of the pandemic were more often intubated and the beneficial effect of dexamethasone was not established at that time. Thus, our result may not be applicable to patients managed in the subsequent waves of the pandemic. However, long-term sequelae affecting the patients of the first wave of the pandemic will have to be managed in the coming years, justifying the report of late findings in these patients. 
In conclusion, a late OP pattern is common 6 months after severe COVID-19 pneumonia, whereas fibrotic changes of limited extent are only seen in one third of patients. $D_{\text {LCO }}$ remains abnormal in the vast majority of patients, including a subset with apparent CT normalisation, possibly due to residual microvascular obstruction.

Thibaud Poitevineau ${ }^{1}$, Guillaume Chassagnon ${ }^{1,2}$, Samir Bouam ${ }^{3}$, Paul Jaubert ${ }^{2,4}$, Chérifa Cheurfa ${ }^{2,5}$, Lucile Regard ${ }^{2,6}$, Emma Canniff ${ }^{1}$, Anh Tuan Dinh-Xuan $\oplus^{2,7}$ and Marie-Pierre Revel $\oplus^{1,2}$

${ }^{1}$ Service de Radiologie, Hôpital Cochin, AP-HP Centre, Paris, France. ${ }^{2}$ Université de Paris, Paris, France. ${ }^{3}$ Département d'informatique médicale, Hôpital Cochin, AP-HP Centre, Paris, France. ${ }^{4}$ Service de médecine intensive-réanimation, Hôpital Cochin, AP-HP Centre, Paris, France. ${ }^{5}$ Service de réanimation chirurgicale, Hôpital Cochin, Paris, France. ${ }^{6}$ Service de pneumologie, Hôpital Cochin, AP-HP Centre, Paris, France. ${ }^{7}$ Département de physiologie, Hôpital Cochin, AP-HP Centre, Paris, France.

Corresponding author: Marie-Pierre Revel (marie-pierre.revel@aphp.fr)

Provenance: Submitted article, peer reviewed.

Conflict of interest: T. Poitevineau has nothing to disclose. G. Chassagnon reports receiving consulting fees from Gleamer outside the submitted work. S. Bouam has nothing to disclose. P. Jaubert has nothing to disclose. C. Cheurfa has nothing to disclose. L. Regard has nothing to disclose. E. Canniff has nothing to disclose. A.T. Dinh-Xuan has nothing to disclose. M-P. Revel reports receiving personal payment from MSD France for lectures, presentations, speakers' bureaus, manuscript writing or educational events, outside the submitted work.

References

1 Jiang F, Deng L, Zhang L, et al. Review of the clinical characteristics of Coronavirus Disease 2019 (COVID-19). J Gen Intern Med 2020; 35: 1545-1549.

2 Huang C, Wang Y, Li X, et al. Clinical features of patients infected with 2019 novel coronavirus in Wuhan, China. Lancet 2020; 395: 497-506.

3 Chen N, Zhou M, Dong X, et al. Epidemiological and clinical characteristics of 99 cases of 2019 novel coronavirus pneumonia in Wuhan, China: a descriptive study. Lancet 2020; 395: 507-513.

4 Froidure A, Mahsouli A, Liistro G, et al. Integrative respiratory follow-up of severe COVID-19 reveals common functional and lung imaging sequelae. Respir Med 2021; 181: 106383.

5 Lerum TV, Aaløkken TM, Brønstad E, et al. Dyspnoea, lung function and CT findings 3 months after hospital admission for COVID-19. Eur Respir J 2021; 57: 2003448.

6 Balbi M, Conti C, Imeri G, et al. Post-discharge chest CT findings and pulmonary function tests in severe COVID-19 patients. Eur J Radiol 2021; 138: 109676.

7 van den Borst B, Peters JB, Brink M, et al. Comprehensive health assessment 3 months after recovery from acute coronavirus disease 2019 (COVID-19). Clin Infect Dis 2021; 73: e1089-e1098.

8 Zhao $\mathrm{Y}$, Shang $\mathrm{Y}$, Song $\mathrm{W}$, et al. Follow-up study of the pulmonary function and related physiological characteristics of COVID-19 survivors three months after recovery. EClinicalMedicine 2020; 25: 100463.

9 González J, Benítez ID, Carmona P, et al. Pulmonary function and radiologic features in survivors of critical COVID-19. Chest 2021; 160: 187-198.

10 Kommoss FKF, Schwab C, Tavernar L, et al. The pathology of severe COVID-19-related lung damage. Dtsch Arztebl Int 2020; 117: 500-506.

11 Han X, Fan Y, Alwalid O, et al. Six-month follow-up Chest CT findings after severe COVID-19 pneumonia. Radiology 2021; 299: E177-E186.

12 Hui DS, Wong KT, Ko FW, et al. The 1-year impact of severe acute respiratory syndrome on pulmonary function, exercise capacity, and quality of life in a cohort of survivors. Chest 2005; 128: 2247-2261.

13 George PM, Wells AU, Jenkins RG. Pulmonary fibrosis and COVID-19: the potential role for antifibrotic therapy. Lancet Respir Med 2020; 8: 807-815.

14 Papazian L, Aubron C, Brochard L, et al. Formal guidelines: management of acute respiratory distress syndrome. Ann Intensive Care 2019; 9: 69.

15 Liu M, Lv F, Huang Y, et al. Follow-up study of the chest CT characteristics of COVID-19 survivors seven months after recovery. Front Med. 2021; 8: 636298.

16 Hani C, Trieu NH, Saab I, et al. COVID-19 pneumonia: a review of typical CT findings and differential diagnosis. Diag Interv Imaging 2020; 101: 263-268. 